\title{
Effect of Ablation on Heat Transfer \& Performance of an Axisymmetric Supersonic Nozzle
}

\author{
M. A. Razia*
}

Center for Fluid Dynamics, Centers for Integrated System Design (CISD), Islamabad, Pakistan

Email: aamiraza1@yahoo.com

\begin{abstract}
The theoretical prediction of heat transfer effects in compressible turbulent flows is fundamentally complex phenomenon. Computational fluid dynamics (CFD) analysis is employed using BaldwinLomax turbulent model to simulate the effect of various nozzle geometry defects on the heat transfer state in supersonic nozzles. The study is done in terms of various heat transfer correlations and analogies by characteristic flow regimes numbers. Theses are calculated from modified Reynolds analogy for laminar flow over flat plate, the Dittus-Boelter correlation for fully developed turbulent flow, Sieder-Tate correlation for turbulent pipe flow with property variation and Bartz correlation for variable cross sections flow. In addition to these, modified Stanton correlation for high speed flows for pipe flow analogy is also used. The contribution of ablation on the formation of new nozzle contours at various regions is simulated using energy equation for charring ablators. The effect of heat transfer correlations on nozzle performance with various geometrical defects is also discussed. In addition to it, the supersonic flow behavior is also simulated in the nozzles in terms of pressure, temperature, Mach number and density distribution with ablated surfaces.
\end{abstract}
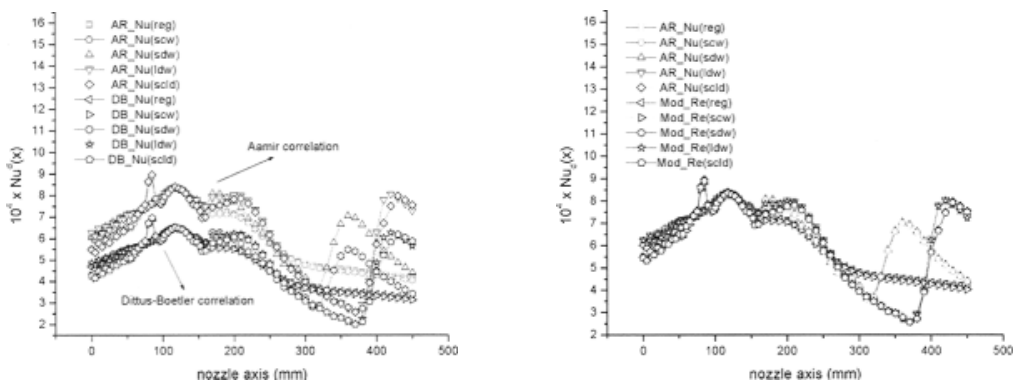

Figure: Local Nu comparison of Aamir\& Dittus-Boetler corrclation and Aamir \& Modified Reynolds correlation

\section{REFERENCES}

1. Incropera F P. Introduction to Heat Transfer. John Wiley \& Sons Ltd, Singaporc, 1985

2. Baldwin, Lomax. Thin layer approximation and algebraic model for separated turbulent flows. AIAA-78-257

3. He $\mathrm{H}$, Zhou X. Ablative control mechanism in nozzle thermo-protection. AIAA-92-3054

4. Mycrs J, Jordan F. Characterizing nozzle behavior as a function of material and configuration. AIAA-84-1310 